\title{
Crisis de PRESENCIA, UNIVERSidAd y POLítica en el nacimiento de la antropología social
de Buenos Aires, Argentina
}

\author{
ROSANA GUBER \\ IDES-CONICET \\ guber@arnet.com.ar
}

\begin{abstract}
Resumen
[N ESTE ARTÍ́CULO ANALIZO LOS FACTORES QUE CONTRIBUYERON AL SURGIMIENTO DEL CAMPO DE LA ["antropología social”, un área de saberes sobre la sociedad y la cultura en la que convergieron de modos particulares el clima político y universitario de la década de I960 y comienzos de la de 1970 en Buenos Aires. Alejada de la problemática indígena y de la inspiración teórica anglosajona, la antropología social porteña se proclamó teórica y políticamente discontinua de las antropologías académicas establecidas en el país y en el exterior. Planteo aquí que la acepción y la práctica de la disciplina, definida como crítica y marginal, y fundada en el compromiso con el destino de sus sujetos de estudio y la transformación social, estuvo marcada por elaboraciones temáticas y teórico-metodológicas connotadas por su imbricación con la política nacional.

Palabras Clave: historia de la antropología, crisis, Argentina.
\end{abstract}

\section{Crisis of PRESENCE, UNIVERSITY AND POLITICS \\ IN THE BIRTH OF SOCIAL ANTHROPOLOGY in Buenos Aires, Argentina}

\begin{abstract}
N THIS ARTICLE I ANALIZE THE FACTORS THAT CONTRIBUTED TO THE EMERGENCE OF "SOCIAL ANTHROPOlogy", a field of knowledge about society and culture where the political and academic climate converged in particular ways in the decade of 1960 and beginning of the I970s in Buenos Aires. Distanced from indigenous issues and anglosaxon theoretical inspirations, Buenos Aires anthropology proclaimed itself theoretically and politically discontinuous from the established academic anthropologies in the country and abroad. I argue that the meaning and the practice of the discipline, defined as critical and marginal, and founded on a commitment with the destiny of its subjects and social transformation, was marked by theoretical, methodological, and thematic constructions deeply imbricated with national politics.

KEY WORDS: History of anthropology, crisis, Argentina.
\end{abstract}

\section{Revista Colombiana de Antropología}

Volumen 43, enero-diciembre 2007, pp. 263-298 
D

ESDE SU NACIMIENTO COMO DISCIPLINA ACADÉMICA, LA ANTROPOLOGÍA atravesó distintas crisis y redefiniciones sucesivas mediante las cuales sus practicantes buscaron situarla en un mundo que veía, en su avasallante globalización, la desaparición de su objeto de estudio. El rescate urgente del "salvaje" (savage slot de Trouillot, I99I), ante la temporalidad infinita y expansiva del capitalismo, el diseño de las fronteras coloniales, las guerras de liberación de la segunda posguerra, fueron algunos de esos hitos con que los expertos rediseñaron su lugar en el concierto de las humanidades y las ciencias. En este proceso participaron ciertamente las escuelas clásicas y los planteos críticos de las academias centrales (Stocking, 2002), pero también los antropólogos que participaban de la formación de escuelas más próximas a los habituales "campos” empíricos de la disciplina. En sus prácticas y reflexiones redefinieron los alcances de su disciplina y, significativamente, su organización interna. En esta redefinición intervinieron no sólo los debates académicos sino también, y a veces muy significativamente, las configuraciones políticas, sociales y culturales de sus países. Así, estos antropólogos de diversa procedencia y trayectoria se convirtieron en artífices de los contextos en que la elaboración académica debía cobrar sentido (Peirano, I99i; Cardoso de Oliveira y Ruben, I995; Vermeulen y Álvarez Roldán, I995; Escobar y Lins Ribeiro, 2005; Boskovic en prensa). En la Argentina uno de esos contextos, probablemente el más altisonante por lo crítico y comprensivo, se llamó "antropología social”.

En este artículo analizo los factores que contribuyeron al surgimiento del campo de la "antropología social”, un área de saberes sobre la sociedad y la cultura en la que convergieron de modos particulares el clima político y universitario de la década de I960 y comienzos de la de I970. En un país cuya sociedad política y civil se concebía como una nación moderna y migratoria, con población indígena y negra exigua, temprana industrialización y extensa urbanización, pero también en un marco de creciente turbulencia política, algunos jóvenes licenciados de la carrera de ciencias antropológicas de la Universidad de Buenos Aires (en adelante UBA), labraron su lugar mediante la nominación de la antropología social como un campo teórica y políticamente discontinuo con las antropologías académicas establecidas en la Argentina y en la metrópolis académica. Más que heredera de su homónima británica o de uno de los cuatro campos de las ciencias antropológicas en Estados Unidos, la antropología social 
porteña fue imaginada como una disciplina crítica y marginal entre las humanidades y las ciencias sociales, fundada, como veremos, en el compromiso con el destino de sus sujetos de estudio y la transformación social. Aun cuando no fuera el único en reconocerse como “antropológico social” (Guber y Visacovsky, 2000), este perfil logró imponerse como el sentido dominante de la disciplina, al menos hasta los umbrales del siglo veintiuno. Su surgimiento no derivó tanto de las demandas de ciertos sectores sociales, formuladas en clave etno-racial, sino de la proscripción política, la radicalización de las juventudes universitarias y la intervención del poder ejecutivo en la Universidad de Buenos Aires. En estas páginas examino los sentidos con que esos primeros antropólogos profesionales se constituyeron a sí mismos y a su especificidad disciplinaria como “antropología social”. Para ello necesitamos hacer un recorrido de época habitado por agentes académicos concretos que tomaron ciertas decisiones en tiempos de dificultad creciente que afectaron su posibilidad de permanecer como reproductores disciplinares en la universidad que los vio nacer. Ello redundó en una acepción y una práctica de la antropología marcada por elaboraciones temáticas y teórico-metodológicas connotadas por su imbricación con la política nacional.

\section{SÓlo Cierto MALESTAR}

AS PRIMERAS EXPRESIONES MÁS O MENOS AUTÓNOMAS DE ESTUDIANTES PRÓXImos a graduarse entre I963 y I965 como licenciados en ciencias -antropológicas, carrera creada en I958 e iniciada en I959, revelaban cierto malestar acerca de los posibles usos de la antropología. En I962 algunos estudiantes alentados por el profesor arqueólogo Ciro R. Lafón, publicaron la revista Anthropológica (Bilbao, 2003, comunicación personal, en adelante c. p.). En sus únicos dos números, los editores y algunos colaboradores presentaban a la antropología como una disciplina "comprometida” con el desarrollo y el cambio social. En su primera nota editorial señalaban que:

no ignoraremos evasivamente la realidad que nos rodea sinó (sic) que nuestro trabajo se proyectará teniendo como meta el análisis y el mejor conocimiento de nuestra cultura y la de los pueblos hermanos de Latinoamérica (1962: 2). 
Blas Alberti, el primero en graduarse (I962), escribía en "Antropología, desarrollo y compromiso":

Los antropólogos de hoy deben comprender que el manejo de estos conocimientos pueden (sic) servir de instrumentos valiosísimos para operar en el seno de las sociedades que encaran su transformación integral (I962: 4).

Para ello, los antropólogos deberían pasar de la "mera descripción" a la "Ciencia" y a la "explicación", suministrando sus diagnósticos y recomendaciones como "activo militante en la 'Batalla de Bienestar' a la que se enfrentan los países en formación" (Ibídem: 6). El antropólogo moderno debía operar con un "compromiso militante" para promover el cambio (Ibídem). La nota editorial del segundo y último número homologaba a la antropología con el cambio social y hacía votos por la reforma del plan de estudios consistente en cuatro años comunes y un año dedicado al trabajo como asistentes en alguna de las tres orientaciones: arqueología, folklore y etnología ${ }^{1}$.

Ni el comité editorial de la revista, integrado por los aún alumnos Santiago Bilbao, Jorge Bracco, Miguel Hángel González y Hugo Ratier, ni sus colaboradores hablaban todavía de "antropología social", sino del "trabajo sobre un problema concreto" (Ratier, en Gurevich, 1989). Bilbao recordaba que "Algunos buscábamos una expresión propia o cercana a nuestra realidad y por eso no le paré (bola) ${ }^{2}$ (...) a las denominaciones” (2003, c. p.). Cuando le pregunté a Leopoldo

I. Resolución del Consejo directivo de la Facultad de filosofía y letras del I de septiembre de 1958.

2. "Parar bola" es, en el habla coloquial de Venezuela, donde residió Bilbao desde I975 hasta su muerte en 2006, "prestar atención". la antropología social, sino que sencillamente me dediqué a lo que consideraba que era antropología” (2003, c. p.).

Dado que la antropología social no tenía existencia institucional en ciencias antropológicas al momento de abrirse la licenciatura porteña, y que a comienzos de la década de 1960 "la antropología" designaba tanto a lo que se impartía en la carrera de ciencias antropológicas en Buenos Aires, como a una profesión que, según sus alumnos imaginaban, podía resolver problemas sociales y acompañar procesos de transformación política y 
social, cabe preguntarse de dónde sacarían estos jóvenes estudiantes dicha denominación.

\section{UNA ORIENTACIÓN SOCIOCULTURAL}

"/ANTROPOlOGía SOCIAL” ERA EL NOMBRE DE UNA MATERIA A CARGO DE LA carrera de sociología, que diseñaba los programas y elegía a sus profesores. La asignatura era optativa para los futuros sociólogos, que de todos modos accedían a sus contenidos en otras asignaturas -"Introducción a la sociología” y en "Sociología sistemática"- y era obligatoria para los estudiantes de antropología. Este carácter mixto, con nombre antropológico y sede sociológica, denunciaba profundas diferencias político-académicas entre ambos departamentos, al frente de los cuales estaban dos italianos. En el Departamento e Instituto de Sociología regía quien es reconocido por la comunidad científico-social como el padre de la sociología moderna en la Argentina, Gino Germani, un parsoniano heterodoxo (Blanco, 2004) que sostenía el ideal unitario de las ciencias sociales y reservaba a la antropología el estudio de la cultura en el espacio y en el tiempo. En sus programas enseñaba las corrientes anglosajonas fundadas por Radcliffe-Brown y Malinowski, el historicismo de Boas, el culturalismo estadounidense de la escuela de cultura y personalidad, y aproximaciones neoevolucionistas y materialistas como las de Leslie White y Julian Steward (Visacovsky, Guber y Gurevich, 1997). En el Instituto de Antropología estaba Marcelo Bórmida (I925-I978), figura emblemática de la antropología formado en Buenos Aires con el americanista antropólogo físico José Imbelloni, rector de la antropología porteña bajo los dos gobiernos peronistas, de fuerte orientación biológica y colaborador del ingreso de la escuela histórico-cultural vienesa en la UBA. Por consiguiente, la vertiente teórica dominante en sociología era el estructural-funcionalismo, y en ciencias antropológicas la escuela histórico-cultural de los círculos culturales, con acercamiento progresivo a una orientación de la fenomenología.

La distancia entre ambos departamentos se ponía de manifiesto no sólo en su dimensión filosófico-teórica estructural-funcionalista estadounidense e historicista humanista germana. Emergía también en las inclinaciones políticas de sus dos conductores. Ambos obtuvieron sus licenciaturas en la Universidad de Roma 
y emigraron a la Argentina por razones políticas. Germani había llegado en I934 con una licenciatura en administración de la Facultad de ciencias económicas, después de pasar un año recluido en una isla italiana por sus simpatías socialistas y su militancia anti-fascista (Neiburg, 1998: I85). Bórmida también llegó exiliado a la Argentina pero en 1947 , debido a su militancia en las filas infanto-juveniles de los Balilla. Bachiller en ciencias naturales en Roma dirigido por el antropólogo raciólogo Sergi, Bórmida inició una ascendente carrera académica con el padrinazgo de su compatriota y correligionario Imbelloni (Garbulsky, 1987, I99I; Fígoli, 2005; Guber, 2006). Se doctoró en Buenos Aires en 1954 con una tesis en craneología, la misma especialidad de su maestro.

Bórmida e Imbelloni eran igualmente renuentes a la antropología social, a la que impugnaban como una rama de la sociología angloamericana, y a la que deploraban como empirista,

3. Alberto Rex González, comunicación personal (2003). Véase Guber, 2006. descriptiva y falta de teoría o, según Imbelloni, como "vano e inútil sociomorfismo"3. Para ellos

se trataba de una especialidad inmadura e imprecisa, falta de tradición y resultados trascendentes.

(...) (la antropología social) ha rebasado el campo y los fines tradicionales de la etnología y ha intentado aplicar los métodos y los principios del funcionalismo a las culturas indígenas en proceso de transculturación occidental -y a la misma cultura occidental- con el fin de comprender y controlar los procesos de cambio. Los resultados prácticos de esta tendencia son aún muy escasos debido tanto al desinterés de las autoridades en aplicar en gran escala los consejos de los antropólogos sociales como también a grandes fallas teóricas en la labor de éstos. Es claro que la antropología social se halla todavía en una fase experimental y no parece aún muy cercano el día en que los resultados concretos compensen la enorme masa de esfuerzos realizados y la inmensa masa de materiales que se ha ido acumulando (Bórmida, 196r: 486).

Pese a su atribuida inexistencia, Bórmida deploraba a la antropología social por tratarse de una vertiente aplicada dedicada al presente y a los problemas concretos, y más próxima a los funcionarios del estado que de la academia.

No es extraño que ni el programa de la asignatura antropología social ni su primer profesor provinieran de ciencias antropológicas. Germani debió tener grandes dificultades para encontrar a 
su docente, lo que ocurrió recién en I962, cinco años después de iniciado el dictado de sociología y tres de ciencias antropológicas. Se trataba de Ralph Beals (I9OI-I985), el primer graduado en antropología de la Universidad de California en Los Angeles (I936), estudioso de los pueblos del sudoeste de Estados Unidos y norte de México, y experto en "guerra”, presidente de la asociación estadounidense de antropología en I950 y enemigo manifiesto de la participación de sus colegas en actividades de contrainsurgencia (Gledhill, 2000: 224). Beals permaneció un semestre como profesor visitante y fue reemplazado al año siguiente por Abraham Monk, quien modificó el viejo título de "antropología social” por el de “antropología social y cultural”, con el debido sesgo culturalista.

Ambos programas instruían en las corrientes de la antropología social y cultural, examinaban temáticas propias de la disciplina -organización social, política, ecología, carácter nacional, aculturación, estudios de comunidad-, promovían el trabajo de campo de los alumnos y les proponían temas para el trabajo final, excluyendo de hecho cuestiones de religión, más atendidas en ciencias antropológicas. Beals y Monk se apoyaban en antropólogos estadounidenses como Ralph Linton, Alfred Kroeber, Oscar Lewis, Ruth Benedict y Michael Lowie ${ }^{4}$. Sin embargo, el autor más citado por los estudiantes era el antropólogo social austríaco Siegfried Nadel (I903-I956) ${ }^{5}$, de clara filiación funcionalista y abogado pionero de la antropología aplicada para la administración colonial británica, gracias a la traducción y sucesivas reediciones de su Introducción a la antropología social por Fondo de Cultura Económica (I95I). El estructural-funcionalismo no estaba totalmente ausente de ciencias antropológicas. Lo impartían el profesor de etnología Enrique Palavecino, y Augusto Cortázar, graduado en letras y luego a cargo de la cátedra de folklore, y creador del "método integral-funcional”6. Sin embargo, y por razones que no he de tratar aquí, su lugar era secundario frente al bloque teórico centro-europeo que campeaba en etnología y arqueología, las dos especialidades fuertes de ciencias antropológicas.
4. Para un análisis más detallado de la época y de sus planes de estudio, véase Visacovsky, Guber y Gurevich, 1997.

5. Después de doctorarse en Viena (I925), fue a la London School of Economics a trabajar con Charles Seligman y Bronislav Malinowski (I932), para casi inmediatamente comenzar a desempeñarse con rango militar, lo habitual para la época y el lugar, como antropólogo del gobierno indirecto sobre los nupe (I934-I936) y los nuba (I938-I939) en el Sudán anglo-egipcio (Boskovic, 2004: 373).

6. Cortázar dirigía la licenciatura en folklore que, junto con la licenciatura de técnico de servicio de museos, precedió a ciencias antropológicas y fueron subsumidas en ella desde I959. 
Las diferencias entre sociología y ciencias antropológicas se comentaban en los pasillos. Profesores y alumnos de la Facultad de filosofía y letras tachaban al departamento de ciencias antropológicas como "cueva de fascistas", atributo a veces intercambiable con el mote de "histórico-cultural", y eje diacrítico de la frontera interdisciplinaria que delimitaba a una comunidad antropológica en la que coexistían de manera bastante integrada profesores y alumnos. El Museo Etnográfico, esa presunta "cueva”, fue la cuna de la licenciatura y el hogar de los antropólogos de Buenos Aires, incluyendo a quienes algún tiempo después comenzarían a proclamarse como "sociales".

\section{Ciencias antropológicas, UNA COMUNIDAD HOMOGÉNEA... Y SEPARATISTA}

De

ESDE SU FUNDACIÓN EN I9O4, LOS CURSOS DE ANTROPOLOGÍA Y ARQUEOlogía del segundo año de la carrera de "profesor de enseñanza secundaria, normal y especial en historia” se dictaban en la

7. Fundado en 1904 por uno de los pioneros de la antropología argentina, Juan Bautista Ambrosetti, fue la primera institución universitaria argentina creada con la finalidad de desarrollar científicamente el estudio del hombre -que comprendía antropología morfológica, arqueología y etnografía-. Hasta allí, los estudios antropológicos eran desarrollados en los museos de ciencias naturales (Fígoli, I99I; Roca, 2005). mansión de dos plantas de la calle Moreno $35 \mathrm{O}^{7}$. Esta antigua casa refaccionada para la exhibición, la investigación y la lectura, estaba tapizada por vitrinas con objetos étnicos y arqueológicos, con dos recintos para alojar al director y un aula. La unidad entre docencia, exposición e investigación era análoga a la que existía en los inicios de los cursos formales de antropología en Europa y Estados Unidos (Vermeulen y Álvarez Roldán, 1995). Esta articulación no dejaba de ser apasionante para quien allí ingresaba, aun cuando no existiera todavía un título específico en antropología. El clima dependía del director, quien podía crear una atmósfera de relativa camaradería e intercambio entre profesores, estudiantes e invitados en una relación que se proponía más plural que la que concedían las jerarquías de la Facultad. En el Museo el alumno interactuaba con su profesor en varios contextos. Clases y conferencias, pasillos, aula y cubículos-oficinas con colecciones, cajas, estantes y documentos: el alumno devenía en asistente de investigación en el Museo y 
también en los viajes de campaña, donde la persona del profesor y de sus alumnos se exhibían con menor pudor (Pegoraro, 2006; Roca, 2006; Guber, 2006; véanse Podgorny, 2004; Soprano, 2006, respecto al Museo de La Plata).

¿Dónde residía la "magia del Museo"?². La sociabilidad de quienes allí transcurrían buena parte de sus días como asistentes, docentes y alumnos se reforzaba con los viajes y las estadías que evocaban los objetos y las colecciones. El “campo” yacía, en vitrinas y estantes, como objeto de genuina veneración de la alteridad humana en el tiempo y el su vez citaba la frase de Malinowski "la magia espacio, y como testimonio de la del etnógrafo".

propia experiencia en tanto "antropólogos" que habían tomado parte de las expediciones conducidas por algunos profesores con sus alumnos desde los tiempos de Juan B. Ambrosetti, su fundador. Los viajes proveían las evidencias y las fuentes donde abrevaban etnólogos, folklorólogos y arqueólogos, a menudo de forma indistinta, para redactar informes de investigación, documentos, artículos para revistas, ponencias para congresos, y monografías para las materias. El Museo Etnográfico se constituía metonímicamente con el viaje y el laboratorio, el nodo de la especificidad antropológica, el cofre de los tesoros de una disciplina que se regodeaba en el exotismo del que participaban, y donde se constituían como tales docentes y alumnos, antropólogos y arqueólogos, maestros y discípulos (Guber, 2006).

En 1988 los primeros alumnos de la licenciatura evocaban aquella magia.

La relación (...) con los profesores era muy cercana, muy cercana. Estábamos todos juntos en las fiestas, íbamos a las casas de los unos y de los otros, éramos un grupo muy homogéneo (Ratier, CGCA, I989: I5; véase Austral, CGCA: I7 y Merlino, CGCA: 20).

Ratier aplicaba el adjetivo "cercano" no sólo a la sociabilidad entre alumnos, sino también a una relación que hasta entonces había sido fuertemente vertical como la de profesores-alumnos (Visacovsky y Guber, 1997). Extremando la horizontalidad, Mirtha Lischetti recordaba la creación de la licenciatura en ciencias antropológicas como resultado de la voluntad de algunos estudiantes del segundo año de la carrera de historia. 
(...) mi recuerdo nos ubica a Eduardo (Menéndez), a Gorita (Carmen Muñoz) y a mí, sentados en los sillones de la antesala del decano Morínigo, en el actual rectorado, para hacerle llegar, de manera personal, la solicitud de la creación de la carrera por parte del claustro de los estudiantes (CGCA, I989: II).

Así,

En julio de 1958 rendimos el examen final de antropología, la materia que daba Bórmida. La rendimos Carmen Muñoz (...), Eduardo Menéndez y yo. Fuimos invitados a comer a casa de los Bórmida, ritual que iba a repetirse con distintos grupos de gente (Ibídem).

Lischetti se refería a Bórmida y a su segunda esposa, Amalia Sanguinetti, egresada como profesora de historia de la Facultad y especializada en prehistoria. Este recuerdo, sin embargo, ubicaba la relación entre el matrimonio Bórmida y Lischetti con sus dos compañeros, en el año 1958, cuando éstos todavía eran alumnos de historia, y un año antes del dictado efectivo de la licenciatura en 1959. También anterior a la apertura del grado pero posterior a la firma de resolución de su creación, fue cuando el is de septiembre de 1958 el decano designaba al estudiante de segundo año de historia, Eduardo Menéndez, como ayudante $5^{\circ}$ rentado en el Instituto de Antropología. Bórmida, director del Instituto, fundamentaba la solicitud de tal designación en la necesidad de "contar con más personal para el mejor desarrollo de las tareas de investigación y documentación en el Instituto a mi cargo" y en que este "destacado alumno" demostraba "un especial interés por las disciplinas que aquí se cultivan", aspirando a "espesialisarse" (sic) en ellas ${ }^{9}$.

Ciencias antropológicas proponía así un modelo de consolidación profesional y académico un tanto distinto del de las otras licenciaturas ya en funcionamiento -sociología, educación

9. Res. Mov. Pers. $n^{\circ} 198$, I5 de septiembre 1958 . Menéndez percibiría $\$ 750 \mathrm{~m} / \mathrm{n}$ mensuales más $\$ 405$ por Dto. $23.573 / 56$. en la Facultad, aparecían como totalmente nuevas y plenamente identificadas con el proyecto modernizador del gobierno y de la universidad posperonista. Rasgos nodales de la modernización en la universidad eran la actualización teórica, preferentemente euro-occidental y estadounidense, y metodológica, la investigación 
empírica y la aplicabilidad del conocimiento a la gestión de gobierno y a la empresa. Lejos de la especulación y el enciclopedismo, las nuevas licenciaturas -ahora incluyendo a geografía e historia, muy renovadas- debían contribuir a la modernización del hombre argentino, de su sociedad, su política y su cultura. La conducción de ciencias antropológicas no se identificaba con este paradigma, miraba al pasado, y lograba incluir, aún con el provecho de un cargo rentado, en un proyecto que preservaba los paradigmas preexistentes, a unos cuantos alumnos que serían los primeros voceros locales de una antropología diferente.

El malestar comenzó a manifestarse después de I96I-I962 entre los estudiantes avanzados de ciencias antropológicas, y se expresaba en esta misma línea. Todo el énfasis de los profesores de antropología en religión, mitología y tradición, como expresiones tardías de la culturología imbelloniana ahora llamada etnología, lo ponían los sociólogos en las categorías sociales construidas con datos cuantitativos. Los estudiantes de historia que decidieron en I958 empujar hacia una carrera aún inexistente en antropología, hacían causa común con un profesor de la vieja antropología. Ni la concepción del plan de estudios ni el contenido de las materias debían resultarles desconocidos: estos “estudiantes fundadores”, ya iniciados en la militancia política de izquierda, acababan de rendir "antropología” con el adlátere de la nueva carrera.

La magia del Museo demoró en desaparecer por varias razones. A esa demora contribuyó decididamente una segregación espacial que remitía a diferencias más profundas.

Yo recuerdo a Blas Alberti dando materias en la facultad y diciéndome: “(...) voy a ir a la facultad a dar algunas (cursar algunas materias) porque si no, voy a estar dos años en la facultad, es decir, voy a estar dos años lejos del Museo". No se podía estar dos años lejos del Museo (Ratier, CGCA: ז3; paréntesis míos).

Los estudiantes de antropología aparecían fuera de su recinto o "cueva", como "el bicho raro" (Ratier, en CGCA, I989: I3) que siempre tenía para apuntar un caso al que no se aplicaba la teoría social general (Herrán, CGCA, I989: 24). Por eso, Carlos A. Herrán, compañero de una cohorte posterior, recordaba a "la gente de antropología” como "un grupo bastante separatista (...) del resto de la facultad" (CGCA: 23). Ese separatismo operaba en dos direcciones: una con respecto a los demás estudiantes de la 
Facultad, y otra con respecto a otros estudiantes de antropología o especializados en esta orientación disciplinar, en el resto del país, aspecto al que volveremos en la próxima sección. Por el momento baste decir que la adhesión, la familiaridad y la sociabilidad endogámica que suscitaba el Museo con sus clases, sus viajes de campaña y sus tareas de clasificación, archivo y análisis, distaban bastante del clima que, al menos para los estudiantes de antropología, reinaba en los demás edificios universitarios, especialmente en el de filosofía y letras "de la calle Viamonte", donde se cursaban las materias extraantropológicas incluyendo, por supuesto, a “antropología social”. La cuestión de los edificios no era menor: el Museo gozaba de una continuidad de la que la Facultad carecía, lo que se vería agravado en los años por venir cuando sociología fue relocalizada a la calle Florida por su afluencia estudiantil, consiguiendo un edificio propio pero ... sin tradición $^{10}$. Edificio y contenidos reforzaban las direcciones opuestas

Io. Filosofía y letras se mudaría luego al viejo hospital de Clínicas, en la zona de las facultades. En 1975, cuando luego filosofía y letras fue escindida, dispersando a alumnos, docentes y no docentes en al menos tres edificios. En I988 se relocalizó nuevamente en un gran pabellón fabril.

de sociología y antropología: presente y pasado, modernidad y tradición -en la jerga teórica dominante de la época-, la Facultad y el Museo. La magia del Museo consistió, pues, en fundar un lugar de tradición que amarraba a sus habitantes incluso a la hora de pensar alternativas. Ello no eliminaba los movimientos a veces tectónicos en su interior, que se fueron acentuando con el devenir político de la Argentina. Pero el Museo todavía le garantizaba a la carrera una presencia segura. La comunidad antropológica parecía disfrutar de cierta paz que contrastaba con un país en crónica crisis política que no demoraría en ingresar a la sede de Moreno 350.

\section{EL INGRESO DE LA FISIÓN}

//LA UNIDAD INICIAL" ENTRE PROFESORES Y ALUMNOS DE CIENCIAS ANTROPOlógicas confirmaba la extraordinaria continuidad de la carrera con respecto al periodo prerrevolucionario (pre 1955): la misma filosofía, las mismas teorías rectoras, los mismos profesores y las mismas metodologías. Aun cuando, como veremos, las diferencias entre profesores y alumnos o jóvenes licenciados no 
demoraron en permear a la academia a la luz de los tumultuosos años 1960, en ciencias antropológicas el proceso fue muy distinto del de las disciplinas hermanas. La antropología social fue la hija de dicho proceso, que comenzó en una búsqueda generada por cierto malestar con el statu quo de ciencias antropológicas. Pero, para que ese malestar dejara el ámbito de las expresiones "meramente juveniles" para traducirse en una alternativa disciplinar haría falta articularlo con otros elementos de orden político interno - la estructura universitaria- y de orden externo -la radicalización de las juventudes y, sobre todo, la intervención del poder ejecutivo en la autonomía universitaria-.

La homogénea "unidad inicial” del medio antropológico se refería a una relación entre alumnos y profesores que debía plantearse como jerárquica (Guber y Visacovsky, I999). Sin embargo, la estructura universitaria que enmarcaba a la licenciatura conspiraba contra esta integración homogénea. Los estudiantes de antropología pertenecían al "claustro” estudiantil de la Facultad, desde el cual aportaban al gobierno tripartito de la universidad junto a, pero separados de, docentes y graduados ${ }^{11}$. Este régimen, suspendido durante la década peronista, se había restituido como parte de la reconquista de la Universidad, proceso en el cual los estudiantes de la Federación Universitaria de II. La autonomía universitaria y el gobierno tripartito por claustro fueron instituidos con la reforma universitaria de I9I8.

orientación radical habían tenido

un papel decisivo. La devoción por el Museo connotaba no sólo una integración a la carrera, sino también "la no participación global en la vida política de la facultad”, y la auto-marginación "de la política de la Universidad. Se automarginaba también, físicamente (...) (sabiéndose) en ese mundo dorado, romántico y tremendamente atractivo del Museo Etnográfico (...) estábamos muy atrapados nosotros en esa vida de comunidad, cara a cara" (Herrán, CGCA: 23-4). Era una suerte de

(...) huída, una evasión de problemas reales en la sociedad nacional. De alguna manera la no participación era el saberse quizás desligados de grandes problemas de la sociedad política que se estaba constituyendo en ese momento y en gran medida se estaba constituyendo a través de la política universitaria (Ibídem).

Herrán aludía a un doble movimiento: el de la política universitaria y el de la radicalización creciente de universitarios e 
intelectuales frente a la política imperialista de Estados Unidos en Santo Domingo, la definición socialista de Castro en Cuba y, muy especialmente, el reconocimiento oficial de las universidades privadas en la nueva ley de educación superior del gobierno de Arturo Frondizi (1958-I962). El dilema entre la lealtad antropológica -el Museo-y la estudiantil -la Facultad- permeó velozmente a los estudiantes de la licenciatura, quienes se vieron en la necesidad de adoptar posiciones más claras en otras instancias públicas.

En 196I los estudiantes de la carrera de historia de Rosario (Universidad del Litoral) convocaron al Congreso de estudiantes de antropología, en el que sólo se aceptaban estudiantes. Presentaron trabajos en las especialidades de arqueología, etnología, antropología física, folklore y antropología cultural, estudiantes pertenecientes a distintas universidades, como los enrolados en las dos licenciaturas antropológicas de la Argentina (La Plata y Buenos Aires) y en las carreras de historia de Córdoba, Rosario y Tucumán, y también de Cuyo y Noroeste ${ }^{12}$. En I988 Ratier re-

I2. Ya desde la década de I930 se venían dictando cursos de arqueología, etnología y antropología (física) en las universidades de Tucumán, Cuyo (Mendoza) y el Litoral (Rosario). Los asistentes porteños al Congreso fueron, entre otros, Blas Alberti, Carlos Aznar, Jorge Bracco, Mario Califano, Miguel Hángel González, Carlos Herrán, Mirtha Lischetti, Eduardo Menéndez, Carmen Muñoz, María Rosa Neufeld, Hugo Ratier. Edgardo Garbulsky y Myriam Tarragó eran anfitriones, Calandra llegaba desde La Plata, Nicolás de la Fuente de La Rioja y Berberián de Córdoba. cordaba que en aquel congreso "a nosotros (los estudiantes de Buenos Aires) se nos tildaba de histórico-culturales y discípulos de Bórmida" y atribuía el mote, al menos en parte, a "cierta envidia de la gente de Buenos Aires, hacia el Museo Etnográfico y hacia el altar budista" (Ratier, CGCA, I989: I4). Se refería a un altar Shinto que Ambrosetti había importado de Japón y que, metonímicamente, se extendía al "claustro" no estudiantil de Moreno 350. Seguidamente, Ratier aclaraba a su audiencia del 88: "ni histórico-culturales ni bormidianos" (partidarios o seguidores de Bórmida), poniendo de manifiesto que claustro, teoría y política se superponían en una imagen inconveniente porque implicaba la adscripción aparentemente incondicional al Museo, y porque dicha adscripción conllevaba cierta orientación teórica y sobre todo política. La imagen debe entenderse pues como una acusación dirigida a jóvenes, progresistas, no claramente diferenciados de sus mayores, ya fueran fascistas o liberales.

El llamado a los primeros concursos para auxiliares docentes de la nueva carrera terminó invistiendo a varios graduados re- 
cientes como profesores subalternos -jefes de trabajos prácticos y ayudantes-. Su carácter de auxiliares los ubicaba como articuladores entre profesores y alumnos, y por tanto como propulsores de algunas relecturas teóricas y prácticas. La visita conducida por Ratier y Bilbao, ayudantes de trabajos prácticos de la materia folklore, a la Feria de Pájaros de Pompeya, un barrio popular del sur capitalino, era parte de un intento de echar una mirada a la propia ciudad donde residían los alumnos.

A las llamadas de atención externa contra la "indiscriminación” de los jóvenes graduados, y a la primera convocatoria a concursos para cargos auxiliares en la nueva licenciatura, vino a sumarse un tercer elemento que puso en vilo la paz del altar. En I964 llegó al Museo una citación judicial al director, para declarar por el involucramiento de un joven hallado muerto en Orán, en el Chaco salteño. Se trataba de un estudiante de antropología de Buenos Aires, quien contaba en su poder con una carta con sello del Museo Etnográfico que lo acreditaba como alumno de la institución. La muerte del joven fue adjudicada por algunos a sus presuntos camaradas guerrilleros, quienes habrían castigado así su deserción del Ejército Guerrillero del Pueblo (EGP) y, por otros, a las fuerzas de seguridad ${ }^{13}$. El suceso comprometía además a otro compañero de antropología, que abandonó el país.

La militancia política reapareció, aun cuando censurada, en otra iniciativa antropológica esta vez promovida por el estado federal. El censo indígena nacional fue dispuesto por el decreto 3998/65 bajo el débil gobierno del radical Arturo Illia (I963-I966), pero comenzó a ejecutarse en I966 después del golpe militar de junio. El director de la carrera, Enrique Palavecino, que murió antes de darle cumplimiento, había reclutado a unos cuantos alumnos del Museo como censistas. Sin embargo, algunos ex

I3. Ambas versiones tienen sus fundamentos. La guerrilla del Ejército Guerrillero del Pueblo, planificada y desarrollada coordinadamente desde Cuba por Ernesto Guevara, era la futura cabeza de ejércitos guerrilleros en Sudamérica. La iniciativa fue llevada a cabo por el periodista argentino Jorge Massetti, cuyo seudónimo para la operación apodada "Sombra" fue "Comandante Segundo", fundador de la agencia cubana Prensa Latina, y admirador absoluto de la experiencia cubana. La historia del EGP fue demasiado breve y combatida por la Gendarmería Nacional al mando del general Julio Alsogaray, que logró infiltrar al grupo y provocar un enfrentamiento donde fue herido "el guerrillero Diego", capturar todas las provisiones y castigar a las filas. El "guerrillero Diego" habría muerto de hambre (Walsh, 1969). alumnos recuerdan la existencia de ciertas "listas negras" que excluían a quienes contaran con ostensible militancia estudiantil. Fuera esto verdad o no, lo cierto es que ninguno de los más activos militantes en política estudiantil participó de la experiencia, y 
que muchos de ellos declinaron su participación por disentir de los ideales del paradigma modernizador. Más tarde, la exclusión de los jóvenes graduados sería un hecho ante la irrupción de la

I4. Menghin había nacido en Meran, Tirol, y se dedicó a aplicar los círculos culturales de la escuela histórico-cultural a la prehistoria. Su carrera académica se desarrolló en Viena, en gran proximidad de quienes dominaron el mundo teórico austríaco hasta I938, Wilhelm Schmidt y sus discípulos del Verbo Divino, Paul Schebesta y Wilhelm Koppers, entre otros. Esta vertiente católica extrema difería de sus primos difusionistas alemanes Fritz Graebner y Bernhard Anckermann, algo más laicos. Pero todos, tanto alemanes como austríacos, eran acérrimos rivales de los funcionalistas locales, cuya principal figura fue Richard Thurnwald. Sin desistir de sus principios racistas, monogenistas y antisemitas, con los cuales habían acompañado a los gobiernos anteriores para justificar los dominios del último poder colonial europeo en llegar al África, los cultores de la escuela histórico-cultural perdieron la contienda contra los funcionalistas que coparon la Universidad de Viena en I938. Algunos de los victoriosos se abocaron a reunir, desde un funcionalismo apto al darwinismo social, la antropología física con la cultural. Entre tanto, y dado el extraordinariamente duro y autoritario control que Schmidt ejerció sobre su grey y sobre la antropología de habla alemana, con simpatizantes en España, Portugal y Francia, los funcionalistas se apoyaron en el régimen nazi para destronar a sus archienemigos difusionistas (Gingrich, 2005). Terminada la guerra Menghin estuvo dos años detenido en los campos de prisioneros Ludwigsburg y Darmstadt, Alemania occidental, donde siguió dando clases de prehistoria, folklore, etnología, religión y artes para otros internos y algunas autoridades.

I5. La carrera político-académica de Menghin había comenzado en I928, como decano de la Facultad de filosofía de Viena, hasta llegar a rector de la Universidad en I935. Pero apenas Austria se anexó a Alemania en 1938, y aun cuando fugazmente por dos meses según Kohl y Pérez Gollán (2002: 565, nota I2), o por cuatro según Fontán (2005), Menghin fue ministro de Cultura y Educación del gobierno pronazi de Seyss-Inquart. La brevedad de su mandato debió derivar de la oposición entre católicos y pietistas en el gobierno, y entre histórico-culturales y funcionalistas en la antropología germana, pero a diferencia de Wilhelm Schmidt, quien huyó con sus discípulos a Suiza, Menghin permaneció en Viena. dictadura militar autodenominada Revolución Argentina, y la dirección de Bórmida del censo y del Departamento tras la muerte de Palavecino a comienzos de 1966 (Lenton, 2004).

Para ese entonces la politización de los estudiantes había alcanzado la médula académica del Museo y se irradiaba al consejo directivo de la Facultad. En I965 un grupo de alumnos pidió la expulsión inmediata de la Universidad del profesor Oswald Menghin (I888-I973), por sus "importantes antecedentes nazis" como ministro de Educación en I938 en la anexión de Austria a Alemania ${ }^{14}$. Philip Kohl y José Pérez Gollán han señalado que por su fe católica Menghin no llegó a integrar el Partido Nazi, pese a sus propias intenciones y a que siempre apoyó la unificación austro-germana ${ }^{15}$.Su llegada a la Argentina en 1948, gracias a un pasaporte oficial, le permitió integrarse inmediatamente al Museo Etnográfico e iniciar varios trabajos en los que buscaba incorporar el área pampeana y Patagonia en los ciclos culturales de la prehistoria mundial. Fue con base en sus méritos académicos que la conducción reformista, democrática y políticamente liberal de la Universidad de Buenos Aires lo reconoció en I957 como profesor 
extraordinario de la Facultad (Kohl y Pérez, 2002: 565-566; Fontán, $2005)^{16}$.

Los estudiantes de antropología conocían a Menghin y buena parte de su obra, además de su persistente devoción por detectar apellidos de origen judío (Neufeld, 2005; Carnese, 2005; c. p.). En 1965 algunos de estos alumnos estaban traduciendo al castellano “documentos probatorios" de sus inclinaciones antisemitas y pro nazis (Neufeld en CGCA, I988), material que habían conseguido por medio del representante es-

I6. Kohl y Pérez Gollán advierten que los prejuicios de Menghin lo llevaban a apoyar el sionismo como vía de solución del problema judío, por considerar imposible su asimilación al pueblo alemán (véanse también Fillitz, 2004; Gingrich, 2005). Pese a su obsesión por identificar apellidos de origen judío entre los estudiantes del Museo (Neufeldm, 2004, 2005; Carnesem, 2005, comunicación personal), su verdadero enemigo era el evolucionismo ateo (563-564). tudiantil en el Consejo Académico de la Facultad, Daniel Hopen, y de la American Jewish Association (Fontán, 2005). La sesión del consejo académico en que se trató el asunto fue presidida por el decano, Luis Aznar, profesor de teoría y metodología histórica y padre de un alumno de la primera cohorte de ciencias antropológicas, lo que hubiera hecho suponer mayor simpatía o seguimiento de la causa. Sin embargo, los docentes encabezados por Bórmida lograron postergar la cuestión indefinidamente.

Congreso de estudiantes, concursos docentes, implicación de alumnos del Museo en movimientos armados, aguas divididas en la participación institucional de ciencias antropológicas en el censo indígena y acusación a una figura teórica medular del departamento terminaron de agrietar los cimientos de la comunidad antropológica con un intento de reorganización académica y dos arribos, el de Esther Hermitte, una antropóloga argentina flamante Ph.D. en Social Anthropology en Estados Unidos, y el de la Guardia de Infantería de la Policía Federal.

\section{LA RUPTURA}

CANTIAGO BILBAO FUE ELEGIDO CASI POR UNANIMIDAD COMO REPRESENTANte de los asistentes y auxiliares de investigación y auxiliares docentes en el Departamento.

Desde ese cargo tratamos junto con Hugo (Ratier), Miguel Hángel (González) y (Jorge) Bracco de cambiar algunas cosas. Muerto 
Palavecino en el 65, creo, la cosa se puso más pareja y llegamos a cambiar la dirección del departamento. Lafón reemplazó a Bórmida. Se nombró a Susana (Chertudi) para dar folklore general y el plan seguiría a volver a Bórmida a dar antropología física (llamada "antropología”), pues ése era su cargo por concurso. En esos momentos llega Esther (Hermitte) al Museo y podría darla ella (a etnología general). Pero la cosa se cayó con el golpe del 66 (Bilbao, 2003; c. p. Mis aclaraciones).

Un sector de los estudiantes graduados o próximos a graduarse y devenidos en auxiliares intentaba reorganizar el departamento redisponiendo las piezas e incorporando una relativamente nueva. El movimiento estaba encabezado, según Bilbao, por los auxiliares de la especialidad de folklore.

En julio de 1965 los diarios porteños La Nación y La Prensa anunciaron el regreso de una flamante doctora en "antropología social" de la Universidad de Chicago y relataban, en breve nota, su extenso trabajo de campo en Chiapas, México. Esther Hermitte era ya conocida por los docentes de ciencias antropológicas. Egresada como profesora de historia en I950, se alejó del Museo en 1947 junto a la exoneración de su maestro Francisco de Aparicio por su protesta contra la ingerencia del gobierno de Perón en la universidad. Bórmida debió conocerla no sólo como discípula de Aparicio, rival de Imbelloni, sino también porque él estaba en la Facultad cuando Hermitte regresó en I950 a hacer sus prácticas de enseñanza y a terminar de una vez su carrera. Las divisiones en el viejo Museo podían ser personales y eventualmente disciplinarias, pero desde 1946 se convirtieron, además y ostensiblemente, en diferencias políticas: un socialista liberal como Aparicio coincidía con otro liberal, Márquez Miranda, en denostar a un "fascista" como Imbelloni, por lo que el alineamiento de los alumnos debió corresponder a estas definiciones y se extendió a ellos anticipando el lugar que los rótulos ocuparían unos años después. Este proceso se agudizó con los avatares de la política, entre el peronismo y el no-peronismo cada vez más antiperonista (Guber, 2006).

En 1957 Hermitte regresó al Museo, bajo el decanato del interventor Alberto Mario Salas, que ella bien conocía como discípulo dilecto de Aparicio. Nombrada como "ayudante $4^{\circ}$ de investigación” rentada del Instituto de Antropología realizó una breve investigación en el centro minero El Aguilar, para la cual solicitó un subsidio a la Facultad, que le fue concedido. En I958, el mismo 
año que la adscripción de Menéndez al Instituto de Antropología, Bórmida solicitó en su carácter de director del Instituto de Antropología la licencia con goce de haberes por un año de Hermitte para cursar "estudios superiores en antropología social" en la Universidad de Chicago. Ahora, en I965, volvía al Departamento de ciencias antropológicas, no a sociología.

En el primer semestre de 1966 Hermitte dictó un seminario sobre etnografía de los "mayas contemporáneos" con el mismo enfoque estructural-funcionalista que había aplicado en su tesis doctoral. En la ocasión no sólo conoció a dos alumnos, Bartolomé y Herrán, que estarían cerca de ella desde entonces, sino que accedió a los primeros graduados de la carrera. Además, dicho seminario la situaba como profesora, aunque no por concurso, del plantel de ciencias antropológicas.

Los intentos de reorganizar el departamento, el reemplazo de Bórmida por Lafón, la presencia institucionalizada de una antropóloga social hablando de indios actuales, la activa presencia gremial y académica de los auxiliares, el espíritu de denuncia política a una autoridad teórica de la antropología oficial, todo esto abría las puertas para el ejercicio de una antropología diferente. A la luz de los avatares políticos y político-académicos, era casi imposible no visualizar a esa "expresión propia o cercana a nuestra realidad", tal como la definía Bilbao, como la iniciativa de una orientación que se definía simultáneamente como política, académica y antropológica. Fue en este contexto que Lafón, plegado al movimiento que lo había llevado a la jefatura del Museo y pese a su formación histórico-cultural y a su admiración por su maestro Imbelloni, señaló que la antropología social, eventual cuarta orientación de la carrera, era un signo de modernización y nacionalización que no implicaba negar las ramas "clásicas", ni introducir una bandera extra académica, esto es, política (Lafón, en Visacovsky et al., 1997).

En suma, a mediados de I966, la misma carrera docente que iniciaban los jóvenes licenciados constituía la base de lanzamiento para otra rama de la antropología. De ella participaba un par de profesores ligados de hecho y por derecho al folklore, Lafón y Chertudi, unos cuantos estudiantes y la primera académica doctorada en "antropología social". Sin embargo, las connotaciones de esta reorganización progresiva ya estaban suficientemente permeadas por lo que en la jerga de entonces se conocía como lo "político-ideológico" y sus consiguientes distinciones. En esta 
clave, Lischetti resumía el proceso de diferenciación en el "altar" treinta años después en el siguiente orden:

(...) nos íbamos alejando de los profesores iniciales, esa mancomunión inicial fue discriminándose cada vez más. Primero nos discriminamos profesores y alumnos, luego nos separaron las orientaciones, los arqueólogos, los etnólogos. Por último nos agrupamos por ideologías políticas y buscando coherentizar (sic) lo uno con lo otro por metodologías científicas. Del grupo inicial algunos optaron por la fenomenología, otros por el estructuralismo o el estructuralfuncionalismo, o bien por el materialismo histórico (Lischetti, CGCA: I2; Guber y Visacovsky, I998).

En sus memorias Lischetti ubicaba significativamente a las teorías y metodologías científicas como un elemento diferenciador en último lugar y para dar legitimidad a diferencias político-ideológicas resultantes, a su vez, de diferencias subdisciplinarias que a su vez reproducían diferencias de los estamentos universitarios. La renovación teórica no procedía de la discusión sobre investigaciones concretas, aun cuando en algún momento posterior se proyectaran sobre ellas.

La llegada de la Guardia de Infantería de la Policía Federal a la Facultad en el atardecer del 29 de julio de 1966, un mes después de la expulsión de Illia por una asonada militar que había emplazado al general J. C. Onganía como presidente de la nación, permitió consolidar a los histórico-culturales y restituir a Bórmida al mando del Departamento, ya muertos los liberales Márquez Miranda en 1961 y Palavecino a comienzos de I966, tras la renuncia masiva de profesores y auxiliares docentes, particularmente en Buenos Aires ${ }^{17}$. La metáfora del nazismo/fascismo

I7. "(...) y en el momento en que parecía que se iba a producir cierto relevo generacional, en que parecía que íbamos a poder acceder a la universidad, llegan 'los bastones largos'" (Ratier, CGCA, I989: I7). revivía en la denominación del evento, cuando sus víctimas y luego los opositores del régimen de la auto proclamada "Revolución Argentina" bautizaron a aquella irrupción policial como "la noche de los bastones largos" evocando la "noche de los cuchillos largos" o purga hitleriana del partido nazi (1933). Entre tanto, las renuncias masivas no podían sino evocar las exoneraciones y renuncias de 1946-I947 bajo la intervención peronista que en antropología había abierto la puerta a otro profesor identificado con el eje, Menghin. 
Volumen 43, enero-diciembre 2007

La mayoría de los auxiliares docentes, todos ellos nuevos licenciados y algunos activos propiciadores de la antropología social, quedaron afuera de la universidad, en protesta por la virulencia de la irrupción policial y observando cierto verticalismo moral con los decanos que se negaron a obedecer a los nuevos interventores ${ }^{18}$. La única profesora de ciencias antropológicas que renunció a su cargo fue Hermitte.

Aquella noche volvía a restaurarse la continuidad con el departamento antropológico original: en etnología Bórmida consolidaba el pasaje de la escuela históricocultural a la fenomenología; en arqueología prehistórica Menghin le concedía una extraordinaria vigencia a la teoría de los ciclos culturales; en folklore, Cortázar promovía su "funcionalismo difusionista”. Bórmida se afirmaba, tras la irrupción institucional, como el "zar de la antropología" (Bartolomé, 1980).

I8. Las renuncias masivas no fueron precedidas por un debate amplio y digamos que orgánico.

En consecuencia los argumentos fueron generalmente provistos ex post facto, es decir, como justificaciones de decisiones ya tomadas. Muchos de los que permanecieron en sus cargos lo hicieron por razones económicas, como sucediera en 1947, aun cuando ahora se sumaban algunas elaboraciones "estratégicas" acerca de lo políticamente más conveniente (según cada ángulo). Quienes criticaban a los renunciantes sostenían que seguramente contaban con otro empleo bien pago, por lo que la renuncia era un lujo que sólo los bien ubicados podían darse (Terán, I99I). Sin embargo, 40\% del plantel docente de 1966 se autoexcluyó de la universidad, siendo el caso más notorio el de Buenos Aires (Barletta, 2000). La mayoría de ese $40 \%$ no tenía otros empleos, lo cual se evidencia en que en exactas las renuncias fueron sucedidas a veces por la emigración y otras veces por una peregrinación por sucesivos puestos en el área privada; en filosofía y letras muchos renunciantes se reubicaron en organismos oficiales (Conicet, Inta, CFI) y cuando pudieron en centros de investigación privados. Este dato no era nada menor: la posibilidad de insertarse en organismos públicos difiere profundamente de lo ocurrido en 1976, siendo que el golpe de 1966 no había constituido a los individuos en miembros de organizaciones delictivas, y por tanto no los persiguió sistemáticamente y hasta la extinción, de manera que varias dependencias oficiales cobijaron a quienes renunciaron de sociología, educación, y también de antropología. Había posibilidades no sólo para el reagrupamiento sino también para la elaboración de alternativas, aunque fuera un tanto más difícil apostar a su EL CISMA mantenimiento y reproducción.

OS LICENCIADOS PORTEÑOS Y LA PROFESORA EN ANTROPOLOGÍA SOCIAL debían proyectarse fuera de la Universidad de Buenos Aires, lo cual tenía sus serias complicaciones en un país con sólo dos carreras de antropología -Buenos Aires y La Plata-, una orientación en Rosario, y sin representación orgánica en las flamantes universidades privadas. El panorama no era tan problemático para Hermitte, quien ya había sido nombrada como "investigadora jefe" de la flamante sección de "antropología social” del Centro de Investigaciones Sociales (CIS) del Instituto Di Tella 
que proclamaba su excelencia en ciencias sociales contratando argentinos doctorados en el exterior, preferentemente en Estados Unidos y Gran Bretaña (Neiburg y Plotkin, 2004). Sin embargo, la decisión de renunciar la alejaba de las aulas y, por tanto, de la posibilidad de transmitir y reproducir en la Argentina lo aprendido en Chicago.

La situación de los licenciados era distinta. Con edades que rondaban los treinta, pero con sólo uno a tres años de graduados, abandonaban la Facultad con más ideas que experiencia. Lanzados a un mercado laboral que desconocía a la antropología fuera de la estrictamente arqueológica y etnológica, y a un mercado académico restringido en sus capacidades e imaginación por razones más políticas que presupuestarias, estos nuevos antropólogos portaban consigo un título que contradecía tanto su prédica social en la universidad como la capacitación que necesitaban para concretarla. En este sentido, la adopción de un nuevo nombre indicaba qué tipo de presencia vislumbraban y esperaban los renunciantes en la coyuntura, aun cuando las reacciones a dicha adopción pudieran ser dispares.

Para Bilbao, por ejemplo, la búsqueda "de una expresión propia o cercana a nuestra realidad" por parte de la antropología debía jugarse en inserciones concretas, más allá de "la pobretona discusión (nominativa que) era en el fondo una puja entre las influencias de las metrópolis de turno, en este caso las europeas y las estadounidenses" (Bilbao, 2003). La carrera de Bilbao se proyectaba lejos de la academia y muy cerca del campo, en actividades de organización de trabajadores rurales. El camino de otros licenciados como Menéndez, Ratier y Alberti fue la carrera académica en un contexto institucional poco proclive aún a la iniciativa y a la creatividad.

Hermitte fue clave en la primera transición, porque desde su posición de renunciante, que compartía con los más jóvenes, les ofrecía un anclaje institucional, el CIS-Di Tella, en una sección que llevaba el nuevo nombre -antropología social- fuera de la academia oficial. Desde su cargo de investigadora jefe obtuvo un contrato por seis meses para Bilbao "para que terminara unos trabajos sobre Santiago del Estero" y se presentara al Inta para encarar el Chaco (Bilbao, 2003). Herrán se convirtió en su asistente de investigación sobre cooperativas de teleras -tejedoras de ponchos y mantas- y productores de pimentón en Catamarca, y Menéndez, Lischetti, Neufeld y Ratier integraron con ella un 
equipo para estudiar "El significado social de la enfermedad"19. El equipo inició sus actividades en 1967 con un grupo de estudio y prosiguió al año siguiente con trabajo de campo etnográfico con médicos, enfermeros, pacientes y sus familiares, sobre la noción de enfermedad, la relación médico-paciente y clase social, en el barrio capitalino de Saavedra (Actualidad Antropológica, I968: I4-I5). Mientras tanto, Menéndez accedía a cargos docentes de materias introductorias a la "antropología” y a la "antropología social”, como docente en dos universidades privadas, Del Salvador y Belgrano, además de haber ganado una beca en el Consejo Nacional de Investigaciones Científicas y Técnicas (Conicet) para estudiar comunidades migratorias en Entre Ríos bajo la dirección de Hermitte.

De todas estas alternativas, sólo la instancia catamarqueña concluyó en un informe final y en varias publicaciones en castellano y en inglés (Hermitte, I972; Hermitte y Herrán, I970, I977). El equipo de salud terminó dispersándose, lo que Hermitte atribuyó a "la falta de trabajo de campo" y sus asistentes a diferencias teórico-ideológicas con la directora del proyecto. La disputa expuesta, desde el punto de vista de los licenciados, en términos teórico-políticos se había trasladado desde la Facultad con Bórmida al Di Tella con Hermitte ${ }^{20}$. Prácticamente todos los asistentes de Hermitte tenían alguna militancia política que ella no desconocía, aun cuando sostuviera, en virtud de su experiencia en la década peronista, la necesaria autonomía del saber académico. Para sus asistentes la supuesta distancia entre política y academia era fácticamente inexistente, políticamente inviable y moralmente inaceptable (Guber, en prensa).

La intimidad entre política y

I9. Ambas cuestiones tenían sus antecedentes en la trayectoria de Hermitte. El proyecto de Catamarca se ligaba con los debates corrientes en Estados Unidos y América latina sobre campesinado y relaciones sociales en el campo, mientras que el de salud se remontaba a su tesis doctoral sobre los usos y sentidos que cobraba la enfermedad causada por brujería en una comunidad bicultural ladino-tzeltal de los Altos de Chiapas (Hermitte, I968, 1970/2004, 2007).

20. Ella siguió trabajando ya con un subsidio del Conicet, con sus asistentes Herrán y Beatriz Alasia de Heredia, una profesora egresada de historia de la Universidad de Córdoba, recomendada por el arqueólogo doctorado en Columbia Alberto Rex González. En esos años, 1969-I970, Hermitte dirigió también el proyecto interdisciplinario "Situación actual de la población aborigen de la provincia del Chaco y políticas para su integración a la comunidad nacional", en convenio entre el Instituto Di Tella y el organismo oficial Consejo Federal de Inversiones. Sus asistentes de campo fueron el historiador Nicolás Iñigo Carrera y el antropólogo platense también recomendado por González, Alejandro Isla (Hermitte, Isla y Carrera, 1996). academia quedaba ratificada con la intervención universitaria por la anulación de los vientos de cambio en el departamento, y por la intrusión de capitales estado- 
unidenses estatales en la investigación antropológica con claros fines estratégicos, como el Plan Camelot en la vecina república de Chile ${ }^{21}$. En este marco y como constitutivo de esta experiencia comenzó a hablarse de la "antropología social" cuya primera

2I. En 1968 se reveló que el Departamento de Defensa de Estados Unidos estaba llevando a cabo una investigación con antropólogos y sociólogos para detectar la disposición popular a la insurgencia. A ello se agregaba la utilización de antropólogos en actividades de contrainsurgencia en Tailandia, Laos y especialmente en Vietnam, con la firme oposición de un puñado de antropólogos sociales de Estados Unidos como el mismo Beals, Gerald Berreman, Eric Wolf y Joseph Jorgensen (Huizer y Mannheim, I967; Jorgensen, I973; Gledhill, 2000; Patterson, 200I). aparición pública se produjo en i968 en Actualidad Antropológica, una revista bimestral con información sobre el quehacer de los antropólogos argentinos publicada por el Museo Dámaso Arce de la ciudad bonaerense de Olavarría. Después de la muerte de Palavecino, su fundador en I963, la dirigía el arqueólogo y etnohistoriador Guillermo Madrazo, no alineado en la orientación histórico-cultural de Buenos Aires. El editorial del segundo número de Actualidad se titulaba la "Antropología social aquí y ahora", y presentaba a esta subdisciplina como nueva en la Argentina, requiriendo mayor debate teórico, trabajo de campo etnográfico y datos precisos y actualizados. No se la definía sólo como una ciencia sino, fundamentalmente, como una "profesión comprometida" con el presente y con la comprensión de los problemas socioculturales según "el estadio de transformaciones por las que atraviesa nuestro país” (I968: I). Apoyándose en aquel Nadel leído en el curso de sociología, el anónimo editorialista señalaba que la antropología social no se limitaba al estudio de los pueblos primitivos, pues también comprendía a "nuestra propia sociedad", siempre desde una perspectiva histórica, rasgo intrínseco a toda verdadera ciencia (I968: 2).

En el siguiente número de la publicación, en una sección final dedicada a comentarios, Menéndez aportaba seis acotaciones al editorial anterior. La primera atribuía su "tardío desarrollo" en la Argentina al "temprano y dominante desarrollo de las orientaciones geotemporales, sobre las históricas y estructurales", generando un "desproporcionado crecimiento de las disciplinas arqueológicas en detrimento de las otras ciencias socioculturales" (Menéndez, I968: 48). El advenimiento de las escuelas "históricoculturales, morfoculturales, fenomenológicas" había promovido el trabajo sobre ciertos objetos y desplazado la atención sobre aquellos "que ulteriormente constituyeron los objetos de la an- 
tropología social" (Ibídem). En su segunda acotación Menéndez identificaba los antecedentes de la antropología social en la labor de "los geógrafos humanos, folkloristas y etnólogos, en especial referidos a grupos marginales", esto es, indígenas y comunidades folk. En la tercera acotación fijaba "dos momentos en el desarrollo de la antropología social Argentina” que la arraigaban en el país e implícitamente en Buenos Aires: "circa 1947” cuando se abordaban "problemáticas no tradicionales, aún dentro de los grupos marginales (indígenas, folk)", abordajes que calificaba de "trayectoria y consecuencias (...) cortas y escasas", y desde I958 cuando la antropología empezó a aplicarse, desde nuevos enfoques teóricos, a otros grupos sociales y a "áreas ecosociales no tradicionales, como las áreas urbanas” (Ibídem: 49). Si bien la perspectiva "reconstructiva y universalista" había prevalecido en el pasado sobre otra más latinoamericana y nacional (Ibídem: 48), la demora comenzaba a enmendarse.

Por eso en la tercera acotación el autor enumeraba "una serie de 'trabajos' e investigaciones de diferentes calidades y orientaciones" dentro de la cual figuraban rosarinos, cordobeses y platenses, y también porteños ${ }^{22}$. En la quinta acotación -la cuarta no consta en el original-remarcaba que pese a querer encuadrarse en "los marcos referenciales teóricos" de la antropología social los resultados de dichos trabajos eran dispares en "lo metodológico", en las técnicas y las formulaciones conceptuales. Su mayor punto de crítica era la deficiente técnica de campo que habitualmente cedía ante la encuesta, y el uso de "modelos y conceptos sociológicos” (Ibídem: 50). La sexta y última se refería a la proliferación de trabajos de antropología social que encaraba

22. Cierta antropología estadounidense hacía punta allí gracias a las huellas que dejara otro argentino con doctorado en Estados Unidos, Alberto Rex González. Graduado de médico pero apasionadamente arqueólogo especializado en arqueología en la Universidad de Columbia, fue alumno de Julian Steward y concebía a la antropología social y a la arqueología como dos manos movidas por el mismo cerebro, las ciencias antropológicas del pasado y del presente. En esta concepción integrativa había sido alentado por sus compañeros de cursos, como Eric Wolf y Sidney Mintz. En la Argentina, González promovió el estudio de área con arqueólogos y antropólogos culturales (Valle de Santa María, Meister, Petruzzi y Sonzogni, I963). El equipo conformado fue el primero que incluyó explícitamente en sus tareas las de la antropología social, aun cuando la conducción del proyecto del sociólogo Meister acabara imponiendo una perspectiva sociológica culturalista (Garbulsky, 2004). personal amateur, y la falta de docentes capacitados adecuadamente en la subdisciplina (Ibídem: 50-5I).

Varias cuestiones surgen de esta "presentación en sociedad" de la antropología social de índole político-académica en el editorial, y académica en Menéndez. Primero, ambos reivindicaban 
a la antropología social como parte de la antropología. Pese a sus perfiles distintivos, el hogar de la antropología social debía seguir siendo el de las ciencias antropológicas, no el de la sociología, lo cual era evidente al radicar este lanzamiento en una revista con información sobre etnología, arqueología, etnohistoria, etnobotánica, lingüística, folklore y antropología cultural.

Segundo, ese hogar era la Universidad de Buenos Aires. Pese a alguna mención al equipo rosarino, los dos hitos que Menéndez reconocía como fundantes se referían a la institucionalidad antropológica en el Museo Etnográfico: 1947, inicio de la dirección de Imbelloni, y 1958, creación de la licenciatura de Buenos Aires. La referencia a Nadel dejaba entrever una lectura común a quienes habían cursado la asignatura homónima en el Departamento de sociología de la UBA. Tercero, el autor identificaba a los dos interlocutores del nuevo campo. Los "geotemporales" y fenomenólogos -Bórmida e histórico-culturales-y los ahistóricos -estructural-funcionalistas y funcionalistas- desde una óptica capitalina, ya que en Rosario y La Plata los interlocutores no eran estrictamente los mismos. Cuarto, Menéndez definía a la antropología social por sus carencias más que por sus propuestas de orden académico. Salvo el estudio o referencia a la propia sociedad, la cuestión urbana, el "aquí y ahora" y el muy general "la consideración de los problemas socio-culturales propios de la etapa de transformación que está viviendo nuestro país" (editorial, I968: I), la antropología social retenía para sí la problemática del racismo y las técnicas de trabajo de campo.

En suma, la antropología social emergía como una promesa de los flamantes licenciados porteños -el autor del editorial y Menéndez- que pese a afirmarse en los antecedentes de Buenos Aires, estaban en 1968 desterritorializados de su universidad y de su Museo.

\section{Conclusiones}

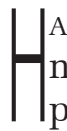
ASTA HACE RELATIVAMENTE POCO TIEMPO, LOS ANTROPÓLOGOS SOLÍAMOS naturalizar las definiciones que las academias metropolitanas proyectaban en el marco mundial. Desde nuestras latitudes buscábamos, y aún seguimos buscando, referir nuestro quehacer a los parámetros instruidos por la ciencia normalizada y los autores 
consagrados, prestando menor atención a las condiciones de producción teórica y empírica con que llenamos un rótulo y organizamos un sistema clasificatorio.

En este artículo quise analizar algunas de las condiciones que modelaron lo que los argentinos entendemos, aún hoy, por “antropología social”. Para ello me interné en los avatares políticoinstitucionales que fueron el contexto para la aparición de esta especialidad, entendida siempre como una subdisciplina antropológica. Lo hice entendiendo por "contexto" no tanto un telón de fondo en el que sucede la escena, sino un marco de significación diseñado para y por los mismos protagonistas de esta historia. Me concentré, entonces, en una determinada localización témporoespacial, cuyo acotamiento puede parecer excesivamente breve, anecdótico y localista si no fuera porque sus cultores, los primeros egresados de la licenciatura en ciencias antropológicas de Buenos Aires, lograron definir, bajo el nombre de "antropología social”, un intersticio académico marcado por su articulación con el devenir político de la sociedad argentina. Esta definición académica tuvo ciertamente inspiraciones teóricas de variada especie -los teóricos de la descolonización, vertientes del marxismo y los ideólogos de la liberación- que se traslucen en los discursos respectivos. Sin embargo, para labrar su posición marginal a la academia central argentina de cara a la etnología de la UBA y al estructural-funcionalismo anglosajón del Di Tella, esa definición hallaba más certezas en el pronunciamiento por una disciplina "comprometida" con el destino de sus sujetos de estudio, destino interpretado como resultante de una coyuntura de crisis y de transformación social. Este posicionamiento se anclaba, mucho más que en la producción de la investigación empírica y los consiguientes debates, en una experiencia institucional académica y nacional.

Esta experiencia suele referirse en la literatura de la época como de "crisis", entendiendo por tal la caída de un orden normativo sustentado, según las interpretaciones, por las contradicciones inherentes al sistema capitalista y por la caída irremediable del colonialismo. Mi análisis de la "antropología social” que nació en Buenos Aires muestra que su surgimiento resulta de una ruptura institucional abonada por un recorrido que partió en 1958 con la conformación de la comunidad antropológica del Museo Etnográfico, donde convivían profesores y alumnos de una carrera específica, la de ciencias antropológicas, y culminó con la renuncia de muchos de esos alumnos ya egresados, a sus cargos 
académicos. En este trayecto los disensos políticos y las búsquedas de alternativas académicas eran tolerables y no amenazaban la convivencia en el hogar porteño de la antropología, pero esa convivencia debió ser resignificada tras la sangrienta intervención universitaria de 1966.

Aun cuando presentara enormes parecidos con los discursos de la antropología crítica en Francia, Inglaterra, Estados Unidos y América latina, y participara del optimismo revolucionario impreso por la revolución argelina y la cubana, y la resistencia de Vietnam, "antropología social" fue en la Argentina el nombre de esa resignificación desde una posición defensiva y tempranamente amenazada de extinción. Antropología social se convirtió en un conjuro capaz de asegurar la supervivencia antropológica de los nuevos licenciados. Me referiré a esta experiencia en los términos de un autor caro a los profesores y alumnos del "altar budista".

Ernesto de Martino, un socialista napolitano graduado en letras y estudioso de religiones comparadas, se dedicó a la etnología y el folklore en el sur de Italia (Saunders, 1984, 1993). Una de sus obras más propiamente etnológicas, Il Mondo Magico, la comenzó a escribir durante la segunda guerra mundial. Allí decía que los llamados pueblos primitivos apelaban a la magia cuando sentían su ser amenazado y visualizaban su posible destrucción, esto es, cuando experimentaban una "crisis de presencia" (I948: I3, 84), "el drama existencial de quedar expuesto al riesgo de no estar ahí" (I973: I4I). Con rituales y fórmulas lograban mantener o restituir la presencia en riesgo. De Martino abrevaba, para formular este concepto, en un diálogo que él establecía entre la filosofía alemana -la idea del Dasein (existencia humana) de Heidegger, y del "sentimiento del yo" o "autoconciencia" de Hegel- y el latah, término malayo que designa un estado de disociación por el cual el individuo se vuelve demasiado susceptible a las influencias externas, imita el movimiento de los otros, se hace eco de sus voces y pierde la integridad de su personalidad. La pérdida de presencia es la pérdida de la conciencia de la persona; su sentido del yo se torna frágil y lábil, se anula su postura activa y queda extremadamente vulnerable ante un shock emocional. En este tipo de crisis el individuo no puede ya distinguir entre su presencia y la del mundo que lo rodea, perdiendo así los límites de su ego. Desde este abordaje más existencial que psicoanalítico, De Martino aclaraba que no era éste ni un fenómeno individual ni 
limitado a los 'pueblos primitivos'. En Naturalismo e storicismo nell'etnologia, en el que Bórmida se inspiraba para elaborar su programa de "etnología general" para la licenciatura, De Martino discutía la crisis de la civilización occidental y afirmaba que el objetivo de los análisis etnológicos debía ser la "expansión de nuestro autoconocimiento para clarificar nuestras acciones". De lo contrario la civilización moderna caería bajo sus mismos designios, en un potencial fin del mundo.

La toma policial de julio de 1966 introducía, por varias razones, todos los elementos de una crisis de presencia demartiniana. Socializados en una universidad cogobernada, donde la excelencia podía garantizar la carrera académica de un graduado, alumnos, graduados recientes y profesores se veían arrastrados por la virulencia de la noche de los bastones largos en defensa de un nuevo sistema de gobierno fundado en los contactos personales extraacadémicos de algunos intelectuales con los políticos golpistas y con ciertas vertientes de la iglesia que oficiaban de consultores de las líneas directivas de las fuerzas armadas. La disyuntiva era inevitable ante lo masivo de las renuncias, particularmente en las facultades porteñas de ciencias exactas y de filosofía y letras. Los efectos de cada decisión individual fueron profundos y duraderos en las relaciones de sociabilidad posterior. En la época y por mucho tiempo después, haber permanecido en la universidad quedaba asociado indefectiblemente al apoyo activo o pasivo a la intervención. Sin embargo, y por otro lado, el futuro era demasiado incierto para los jóvenes graduados que de ahí en adelante deberían desarrollar la antropología fuera del ámbito universitario nacional. El desafío era aún más duro para quienes abogaban por una antropología "del aquí y ahora” en contraposición a una etnología de las esencias inmanentes de los pueblos indígenas. Librados a su suerte institucional, que no les fue adversa por entonces considerando sus inserciones en universidades provinciales y privadas, y en entidades federales y provinciales, aquellos jóvenes podrían impulsar nuevas modalidades antropológicas según los requerimientos de sus inserciones respectivas. Pero que alguna de esas modalidades se llamara "antropología social" fue el resultado de cuanto sucedió después de I966, cuando sobrevino la gran ruptura o "crisis de presencia" de los jóvenes graduados condenados a elegir entre un régimen autoritario, que identificaban como "etnológico", y un régimen pluridisciplinario. Fue en torno al nombre "antropología social" 
que algunos graduados renunciantes de Buenos Aires comenzaron a labrar un espacio propio que se diferenciara del oficial universitario, esgrimiendo su misión histórica de incidir en los problemas del presente. Apostando más a la reiteración de estos principios que a un amplio respaldo de producción académica teórico-empírica, la antropología social fue el conjuro mágico que, al concederle un nombre, terminó consolidando una alternativa que contaba todavía con más promesas que realizaciones. En I974, a un año de una nueva apertura democrática (mayo 1973) y a meses de su mismo cierre (julio 1974), la Argentina contaba con tres flamantes licenciaturas en "antropología social" -en la provincial de Mar del Plata estaba Menéndez; en Salta Mario Gatti, y en Misiones Leopoldo Bartolomé-, y tres especializaciones en las carreras de grado de Buenos Aires, La Plata y Rosario. No casualmente, y salvando el caso de Misiones, la fórmula "antropología social" fue inmediatamente puesta bajo sospecha para ser luego sistemáticamente perseguida y erradicada. La especialidad acabó consolidando su sentido contestatario en un camino que se profundizó con la intervención peronista reaccionaria de 1974 a las universidades nacionales y provinciales, y con los años de plomo del Proceso de Reorganización Nacional (1976-I983). Al cabo de este periodo las investigaciones socio-antropológicas sistemáticas eran un puñado que se remontaba a lo hecho entre I970 y 1975. Buena parte de aquellos inquietos antropólogos de la primera cohorte del Museo dejó el país, y la mayoría lo hizo para siempre. La utopía a la que muchos adhirieron como su "antropología social" quedó amenazada de muerte en la imposibilidad institucional o el exilio y la disolución de un yo académico más imaginado en términos políticos que ejercido en términos analíticos. Recién desde 1984 comenzó la enseñanza de la antropología social en las universidades nacionales y con ello puede decirse, comenzó a equiparse en la Argentina una antropología social con alternativas, continuidad y sustento institucional.

\section{Bibliografía}

AA. ACtUalidad ANTROPOlÓGICA. "Antropología social, aquí y ahora”, i-3 (I968).

Alberti, Blas. "Antropología, desarrollo y compromiso". Anthropológica, I (I962): 3-9. 
Barletta, Ana M. "Universidad y política. La peronización de los universitarios (I966-I973)”. LASA Proceedings, 2000.

BARTolomé, Leopoldo. "La antropología en Argentina: problemas y perspectivas”. América Indígena, XL (2) (I980): 207-2I5.

. "El pensamiento mítico en la veterinaria folklórica”. Runa, XI (I968): 7I-92.

BARTOlOMÉ, LEOPOLDO y EnRIQUe Gorostiaga, editores. Estudios sobre el campesinado latinoamericano. La perspectiva de la antropología social. Buenos Aires: Editorial Periférica, I974.

Bilbao, Santiago Alberto. "Cinco movimientos juveniles rurales; reseña comparativa”. Presidencia Roque Sáenz Peña, Chaco (inédito), I968.

"Migraciones estacionales, en especial para la cosecha del algodón en el norte de Santiago del Estero". Cuadernos del Instituto Nacional de Antropología, 7 (I968-I97I): 327-365.

-Poblamiento y actividad humana en el extremo norte del Chaco Santiagueño”. Cuadernos del Instituto Nacional de Antropología, 5 (I964-I965): I43-I92.

Blanco, Alejandro. "La sociología: una profesión en disputa". En Intelectuales y expertos. La constitución del conocimiento social en la Argentina, compilado por Federico Neiburg y Mariano Plotkin. Buenos Aires: Editorial Paidós, 2004.

BórmidA, MARCElo. "Ciencias antropológicas y humanismo". Revista de la Universidad de Buenos Aires, 6 (3) (I96r): 470-490.

" “Cultura y ciclos culturales. Ensayo de etnología teorética”. Runa, VII (I) (I956): 5-28.

Boskovic, Aleksandar. "Siegried Nadel”. En Biographical Dictionary of Social and Cultural Anthropology, editado por Vered Amit. Londres: Routledge, 2004.

Boskovic, Aleksandar, editor. Other people's anthropologies. Nueva York: Berghahn Books. En prensa.

Briones, Claudia N. y Rosana Guber. “Contagious marginalities. Objects and subjects in Argentine ethnology, social anthropology and folklore". En A Companion to Latin American Anthropology, editado por Deborah Poole. Oxford: Blackwell. En prensa.

Cardoso de Oliveira, Roberto y Guilhermo Raul Ruben. Estilos de antropologia. Campinas: Unicamp, I995.

Colegio de Graduados en Ciencias Antropológicas (CGCA). Jornadas de antropología: 30 años de la carrera en Buenos Aires (I958-I988). Buenos Aires: Universidad de Buenos Aires, Facultad de filosofía y letras, I989. 
Escobar, Arturo y Gustavo Lins Ribeiro, compiladores. World anthropologies. Disciplinary transformations within systems of power. Oxford: Berg, 2005.

Fígoli, LeOnARDo. "Origen y desarrollo de la antropología en la Argentina: de la Organización Nacional hasta mediados del siglo XX”. Anuario de Estudios de Antropología Social, I (2005): 7I-82.

"A antropologia na Argentina e a construçao da naçao". En Estilos de antropologia, compilado por Roberto Cardoso de Oliveira y Guilhermo Ruben. Campinas, Unicamp, I995 (traducción publicada en Anuario de Estudios en Antropología Social. Buenos Aires: CASIdes).

Fillitz, Thomas. "From the dictate of theories to discourses on theories-Teaching and learning social anthropology in Vienna". En Educational histories of European social anthropology, editado por Dorle Dracklé, Iain Edgar y Thomas K. Schipper. Nueva York/Oxford: Berghahn Books, 2004.

FontÁn, MARCELINO. Oswald Menghin: ciencia y nazismo. El antisemitismo como imperativo moral. Buenos Aires: Fundación Memoria del Holocausto, 2005.

GarbUlSKy, EDgardo. "La producción del conocimiento antropológicosocial en la Facultad de filosofía y letras de la Universidad Nacional del Litoral entre I956-I966. Vínculos y relaciones nacionales”. Cuadernos de Antropología Social, 20 (2004): 4I-60.

. "La antropología social en la Argentina”. Runa, XX (I99II992): II-34.

"José Imbelloni, positivismo, organicismo y racismo". Cuadernos de la Escuela de Antropología, 3 (87) (I987).

Gingrich, ANDRE. “The German-Speaking countries”. En One discipline, four ways. British, German, French and American anthropology. Fredrik Barth, Andre Gingrich, Robert Parkin y Sydel Silverman. Chicago: The Chicago University Press, 2005.

Gledhill, John. Power and its disguises. Anthropological perspectives on politics. Londres: Pluto Press, 2000.

Gorbak, Celina, Mirtha Lischetti y Carmen Muñoz. "Batallas del Chiaraje y del Tocto”. Anthropológica, 2 (I963): 3-I7.

Guber, Rosana. "Committed or scientific? The Southern whereabouts of social anthropology and Antropología Social in 1960-70 Argentina”. En Other people's anthropologies, editado por Aleksandar Boscovich. Nueva York: Berghahn Books. En prensa a. 
"Antropólogos ciudadanos (y comprometidos) en la Argentina. Las dos caras de la 'antropología social' en I960-70”. Journal of the World Anthropologies Network. En prensa b.

"Linajes ocultos en los orígenes de la antropología social de Buenos Aires". Avá. Revista del Postgrado en Antropología Social de la Universidad Nacional de Misiones, Argentina, 8 (2006): 26-56.

"Antropología Social: An Argentine diaspora between revolution and nostalgia”. Anthropology Today, I8 (4) (2002): 8-I3.

Guber, Rosana y Sergio E. Visacovsky. "The Birth of Ciencias Antropológicas at the University of Buenos Aires, I955-I965”. Histories of Anthropology Annual, 2 (2006): I-32.

"Nación, marginalidad crítica y el Otro interno en la antropología social argentina de los ig6os-70s”. Desarrollo Económico. Revista de Ciencias Sociales, 40 (I58) (2000): 289-316.

" "Controversias filiales: la imposibilidad genealógica de la antropología social de Buenos Aires”. Relaciones de la Sociedad Argentina de Antropología, XXII-XXIII (I999): 25-53.

Gurevich, Estela. “Entrevista a Blas Alberti”. Buenos Aires. Manuscrito. I989a.

. "Entrevista a Hugo Ratier”. Buenos Aires. Manuscrito. I989b.

Hermitte, Esther. Chiapas en las notas de campo de Esther Hermitte. Rosana Guber y Andrés Fábregas Puig, coordinadores. GTTCE (org.). San Cristóbal Las Casas/Buenos Aires: Universidad Intercultural de Chiapas-Centro de Antropología Social, Ides, 2007.

—. Asistencia técnica en materia de promoción y asistencia de la comunidad en la provincia de Catamarca. Buenos Aires: Consejo Federal de Inversiones, 1972

- Poder sobrenatural y control social. México: Instituto Indigenista Interamericano, 1970. Reedición en 2004, Buenos Aires: Editorial Antropofagia.

"La movilidad social en una comunidad bicultural”. Revista Latinoamericana de Sociología, I (I968): 6-37.

Hermitte, Esther y Carlos A. Herrán. "Sistema productivo, instituciones intersticiales y formas de articulación social en una comunidad del noroeste argentino". En Procesos de articulación social, editado por Esther Hermitte y Leopoldo J. Bartolomé. Buenos Aires: Amorrortu Editores, 1977 .

“¿Patronazgo o cooperativismo? Obstáculos a la modificación del sistema de interacción social en una comunidad del noroeste argentino". Revista Latinoamericana de Sociología, 2 (I970): 293-317. 
Hermitte, Esther y Leopoldo J. Bartolomé, compiladores. Procesos de articulación social. Buenos Aires: Amorrortu Editores, I977.

Hermitte, Esther y equipo (Nicolás Iñigo Carrera y Alejandro Isla, orgs.). Estudio sobre la situación de los aborígenes de la Provincia del Chaco, y políticas para su integración a la sociedad nacional. Posadas: Editorial Universitaria. 3 volúmenes, 1996.

Herrán, Carlos A. "Antropología social en la Argentina: apuntes y perspectivas”. Cuadernos de Antropología Social, 2 (2) (I990): Io8-II5.

Huizer, Gerritt y Bruce Mannheim. The Politics of Anthropology. The Hague: Mouton, I979.

Jorgensen, Joseph G. "On ethics and anthropology”. En To See Ourselves, editado por Thomas Weaver. Glennville, Illinois: Scott Foresman, I973.

Kohl, Philip L. y José A. PÉrez Gollán. "Religion, politics, and prehistory. Reassessing the lingering legacy of Oswald Menghin”. Current Anthropology, 43 (4) (2002): 56I-586.

L’Estolle, Benoît de, Federico Neiburg y Lygia Sigaud, organizadores. Antropología, impérios e Estados nacionais. Río de Janeiro: Relumé Dumará, 2002.

LAFón, Ciro RenÉ. "Notas de etnografía huichaireña”. Runa, XII, partes I-II (I969-I970): 273-328.

. "Fiesta y religión en Punta Corral (Pvcia. de Jujuy)". Runa. Archivo para las Ciencias del Hombre, X, partes I-2 (I960-I965): 256-287.

Lenton, Diana. “'Todos éramos desarrollistas...' La experiencia del Primer Censo Indígena Nacional”. Etnía, 46-47 (2004): 187-206.

Meister, Albert, Susana Petruzzi y Elida Sonzogni. Tradicionalismo y cambio social. Rosario: Universidad Nacional del Litoral, Facultad de filosofía y letras, I963.

MENÉNDEZ, EduARDo L. "Correo antropológico”. Actualidad Antropológica, 3 (I968): 48-5I.

"Proceso de asimilación de inmigrantes europeos a una comunidad rural-urbana de la provincia de Entre Ríos”. Manuscrito, I967-I968.

Neiburg, Federico G. Los intelectuales y la invención del peronismo. Buenos Aires: Editorial Alianza, I998.

Neiburg, Federico G. y Mariano Plotkin. "Los economistas. El Instituto Torcuato di Tella y las nuevas elites estatales en los años sesenta”. En Intelectuales y expertos. La constitución del conocimiento social en la Argentina, editado por Federico G. Neiburg y Mariano Plotkin. Buenos Aires, Paidós, 2004. 
Patterson, Thomas C. A social history of anthropology in the United States. Oxford: Berg, $200 \mathrm{I}$.

Pegoraro, Andrea. “'Instrucciones' y colecciones de viaje. Redes de recolección entre el Museo Etnográfico y los territorios nacionales”. Anuario de Estudios en Antropología Social, (2005): 49-64.

Peirano, Mariza. Uma antropología no plural: tres experiencias contemporaneas. Brasilia: Editora Universidade de Brasilia, I99I.

PoDGorny, IrINA. "Antigüedades incontroladas. La arqueología en la Argentina. I9IO-I940”. En Intelectuales y expertos. La constitución del conocimiento social en la Argentina, editado por F. Neiburg y M. Plotkin. Buenos Aires: Paidós, 2004.

Ratier, Hugo. Cabecita negra. Buenos Aires: Centro Editor de América Latina, I97ı.

- Villeros y villas miseria. Buenos Aires: Centro Editor de América Latina, I97Ib. 5 (I967): I-2.

"Antropología urbana: una experiencia comparativa". Etnía,

I969. "De Empedrado a Isla Maciel. Dos polos del camino migratorio”. Etnía, 9 (1969).

Roca, Andrea. "Objetos ajenos, historias compartidas: los usos del tempo en un museo etnográfico”. Tesis de maestría. Río de Janeiro, Programa de posgrado en antropología social, Museu Nacional de Rio de Janeiro, 2006.

"El Museo Etnográfico Juan B. Amborsetti?: los usos del tiempo en una colección de pasados”. Anuario de Estudios de Antropología Social, (2005): 65-88. Runa, VII (I956). Ia parte.

SAunders, George R. “'Critical ethnocentrism' and the ethnology of Ernesto de Martino”. American Anthropologist, 95 (4) (1993): 875-893

- "Contemporary Italian cultural anthropology". Annual Reviews of Anthropology, I3 (1984): 447-466.

Soprano, Germán. “Continuidad y cambio en los estudios en etnología de poblaciones indígenas contemporáneas y comunidades folk en la Facultad de Ciencias Naturales y Museo de la Universidad Nacional de la Plata (I930-1976)”. Anuario de Estudios en Antropología Social, (2006): 23-52.

Stocking, George A. (Jr.). "Delimitando la antropología: reflexiones históricas acerca de las fronteras de una disciplina sin fronteras”. Revista de Antropología Social, II (2002): II-38.

Terán, Óscar. Nuestros años sesenta. Buenos Aires: Puntosur, I99I. 
Trouillot, Michel-Rolph. "Anthropology and the Savage Slot”. En Recapturing anthropology. Working in the present, editado por Richard Fox. Santa Fe, Nuevo Mexico: School of American Research Advanced, Seminar Series, I99I.

Vermeulen, Han F. y Arturo Álvarez Roldán, editores. Fieldwork and footnotes. Studies in the history of European anthropology. Londres: Routledge, I995.

Vessuri, Hebe M. C. "Land tenure and social structure in Santiago del Estero, Argentina”. Tesis doctoral, Oxford, University of Oxford, Linacre College, I97I.

VisAcovsky, Sergio E. "Santiago Bilbao y el folklore como pasaje a una antropología de la gestión estatal”. En Historias y estilos de trabajo de campo en Argentina, editado por Sergio Visacovsky y Rosana Guber. Buenos Aires: Editorial Antropofagia, 2002.

Visacovsky, Sergio E., Rosana Guber y Estela Gurevich. "Modernidad y tradición en el origen de la carrera de Ciencias antropológicas de la Universidad de Buenos Aires”. Redes, Io (I997).

Visacovsky, Sergio E. y Rosana Guber, compiladores. Historias y estilos de trabajo de campo en Argentina. Buenos Aires: Editorial Antropofagia, 2002.

Walsh, Rodolfo. Prólogo. Ricardo Massetti. "Los que luchan y los que lloran”. En Historia del EGP en Argentina. Editorial Último Recurso, (I969) 2005. 